\title{
Second thoughts about who is first: the medical triage of violent perpetrators and their victims
}

\author{
Azgad Gold, ${ }^{1}$ Rael D Strous ${ }^{1,2}$
}

\begin{abstract}
'Beer Yaakov Mental Health Center, Beer Yaakov, Israel ${ }^{2}$ Sackler Faculty of Medicine, Tel Aviv University, Israel
\end{abstract}

Correspondence to Dr Azgad Gold, Psychiatry, Law and Ethics Unit, Beer Yaakov Mental Health Center, PO Box 1, Beer Yaakov 70350, Israel; azgad.gold@moh.health.gov.il

Received 25 February 2016 Revised 21 July 2016 Accepted 8 August 2016 Published Online First 29 August 2016

\section{SLinked}

- http://dx.doi.org/10.1136/ medethics-2016-103839

- http://dx.doi.org/10.1136/ medethics-2016-103840

\section{CrossMark}

To cite: Gold A,

Strous RD. J Med Ethics

2017;43:293-300.

\section{ABSTRACT}

Extreme intentional and deliberate violence against innocent people, including acts of terror and school shootings, poses various ethical challenges, some related to the practice of medicine. We discuss a dilemma relating to deliberate violence, in this case the aftermath of a terror attack, in which there are multiple injured individuals, including the terror perpetrator. Normally, the priority of medical treatment is determined based on need. However, in the case of a terror attack, there is reason to question this. Should the perpetrator of extreme violence receive medical treatment on the scene before the victims if he or she is designated as the most seriously injured? Or rather, should victims receive medical care priority if they are also in some lifethreatening danger, although not at the same level of severity as the perpetrator? We present two opposing approaches: the conventional 'no-exceptions' approach, which gives priority to the terrorist, and the justiceoriented 'victim first' approach, which gives priority to the victims. Invoking concepts of retributive justice, distributive justice and corrective justice, this latter approach suggests that 'value-neutrality' can lead to injustice. Perpetrators of terror-like violence should be treated as an act of humanism and good ethical medical practice. However, in clear and obvious terror-like situations, to treat the perpetrators of violence before their victims may be unjust. Thus, in some specific situations, the 'victim first' approach may be considered a legitimate alternative triage policy.

...all law is universal but about some things it is not possible to make a universal statement which shall be correct.... When the law speaks universally, then, and a case arises on it which is not covered by the universal statement, then it is right... to correct the omission... this is the nature of the equitable, a correction of law where it is defective owing to its universality... It is plain, then, what the equitable is, and that it is just and is better than one kind of justice...

(Aristotle, The Nicomachean Ethics, book V, p. 99) ${ }^{1}$

\section{WORST-FIRST MEDICAL TRIAGE}

Medical triage, which may be defined as the method of deciding the priority of patients' treatments, is fraught with ethical dilemmas. ${ }^{2}$

According to the Oxford dictionary, the French-origin word triage means 'the process of determining the most important people or things from amongst a large number that require attention'. In the medical context, the definition of the dictionary becomes more specific: 'the assignment of degrees of urgency to wounds or illnesses to decide the order of treatment of a large number of patients or casualties'. This definition implicitly illustrates the dominance of the conventional approach according to which medical attention in emergency situations should be determined based on the degree of urgency (the 'worst-first' approach).

It seems to be current consensus that in medical emergency situations those with remote or no prospects of survival are 'triaged out' and only those at the second stage of severity, with a reasonable likelihood of survival despite their life-threatening status, are prioritised for medical attention. Among this group, the conventional approach holds that priority to medical treatment is determined solely based on need, namely, the level of injury.

The conventional approach (which may be characterised as universal and impersonal) would state that from the physician's perspective, all medical emergencies are equal. Medical treatment should be provided in an objective manner regardless of any background considerations regarding the value of those injured or the cause of the situation that required their intervention. Once medical care is required, the value of distributive justice ${ }^{3}$ mandates that it should be delivered blindly in a nondiscriminating manner based on need. According to this view, from an ethical perspective, there is no essential difference between a medical emergency that stems from a vehicle accident, a natural disaster or a terror attack (hence it is universal). In all medical emergencies, healthcare providers should prioritise medical treatment based on the level of injury, irrespective of the identity of the person who requires the medical treatment (hence it is impersonal).

The historical origin of this priority-based-on-need approach-or the 'worstfirst' approach—can be traced back to Baron Dominique Jean Larrey (1766-1842), a French military surgeon during the Napoleonic period. ${ }^{4}{ }^{5}$ Until his era, the priority of medical care provided to wounded soldiers at the battlefield had been class-based. 'Most of the medical resources were reserved exclusively for officers, soldiers would often have to wait for days or go without treatment'. ${ }^{6}$ Contrary to this tradition, Larrey treated the most seriously wounded first, 'without regard to rank or distinction'. ${ }^{7}$

Indeed, the 'worst-first' approach seems to be the default rule that dominates the realm of modern emergency medical triage. 
In this paper, we raise second thoughts concerning the application of this approach indiscriminately. Specifically, we propose that under certain conditions in the aftermath of some violent events, the victims may be treated before the perpetrator of the violent act. The situation of medical emergency caused by a terror attack will serve as a case study in which our argument will be analysed and illustrated.

\section{ETHICAL CHALLENGES OF TERROR}

Recent terror attacks have led public leaders to re-examine the appropriateness of traditional conventions and practice in addressing the manifold challenges of terror. The vicissitudes of the nature of armed conflicts in the late 20th and 21st centuries have forced legislators and scholars to rethink the legitimate means and boundaries that should be applied in the war against terrorism. ${ }^{8-13}$ The basic distinction between soldiers and civilians, which has a pivotal role in the international laws of war, ${ }^{14}$ is of limited value in the context of terror, since terrorists are usually neither part of an organised army of a state, nor innocent civilians. ${ }^{15} 16$ It seems that in spite of a robust and scholarly effort, consensus pertaining to appropriate solutions to address the challenge of terror has not been achieved. In fact, there remains controversy even with regard to basic concepts, such as the definition of terrorism. ${ }^{17-24}$

The ramifications of terror are pervasive, found in many realms including the economic, social, political and psychological, to name just a few. One major system required to deal with the consequences of terror is the healthcare arena. The provision of medical treatment in times of terror is a challenging task, both from a pure medical ${ }^{5}{ }^{25}$ and ethical perspective. ${ }^{26}$ Medical ethics during times of war may not be synonymous with medical ethics in peacetime. ${ }^{27}$ In light of the various moral quandaries in other arenas that have been raised due to the unique characteristics of terror, it is not surprising that some of the physicians' basic professional traditions and conventions have been called into question.

Two major topics that have attracted much attention in the literature are physicians' involvement in the interrogation of detainees for intelligence gathering ${ }^{28-30}$ and the dilemma concerning the provision of medical treatment to terrorists. ${ }^{31}$ The medical community's response to these dilemmas has highlighted the fact that even in war and other times of conflict 'the therapeutic mission is the profession's primary role and the core of physicians professional identity'. ${ }^{32}$ Having said that, when facing the consequences of terror, it is still not always clear what the specific implications of the 'therapeutic mission' in complex situations should be.

Here, we discuss a dilemma relating to medical triage after a terror attack that has received minimal attention. This situation will serve as a case study for medical triage in unique situations in which both the perpetrator of an extreme and overt violent act and his or her victims require immediate medical attention. Terror is one example of a more general class of cases to which the argument pertaining to the medical triage of extreme violent perpetrator and their victims would apply.

\section{THE TERROR-TRIAGE DILEMMA}

The first line of dealing with the aftermath of a terror attack lies with the medical field and its responsibility to manage acute casualties. The question arises: Is the conventional approach that prioritises medical treatment solely based on need appropriate in a situation regarding a clear and obvious perpetrator of terror? Should a terrorist enjoy the same priority (according to the level of injury) as any other injured individual?
It must be noted that this dilemma only arises when there is a scarcity of resources and manpower, with the assumption that prioritising the terrorist under triage conditions would significantly compromise the victims' lives.

For example, a terrorist has been shot by a policeman after he or she had stabbed and injured five civilian bystanders, for example, five elderly ladies with shopping bags in their hands, or alternatively, five young preschool children waiting for their parents. Should the injured terrorist receive medical treatment on the scene before the victims if he or she is designated as the most seriously injured? Or rather, should the stabbed victims receive medical care priority if they are also in some lifethreatening danger, although not at the same level of severity as the terrorist?

Before directly addressing the terror-triage dilemma, it seems necessary to briefly refer to potential criticism that may dismiss this dilemma from the outset due to ontological and epistemic concerns.

First, a conceptual concern may stem from a moral relativistic perspective, expressed by the saying 'One man's terrorist is another man's freedom fighter'. According to this view, the 'evil' that many ascribe to terror is based on one's subjective view of a particular situation. Hence, there are no 'real' terror attacks that call for special treatment in terms of medical ethics.

A less radical approach may agree that ontologically, there are events that can be defined as terror attacks, which can justifiably be condemned on moral grounds. However, it may be argued that there is no such thing as 'a clear and obvious' situation of a terror attack since it would not be possible to determine immediately after a violent event that it is a case of terrorism, nor would it be possible to differentiate at the scene between the perpetrator of terror and his or her victims.

Thus, these critics would declare, on either conceptual or practical grounds, that the terror-triage dilemma fails since there are no objective means for addressing it.

This criticism may be opposed. First, although terrorism may be hard to define, it is quite real, as most people 'know it when they see it'. Our simplified definition of terrorism is: a deliberate violent act targeted against innocent people in order to promote a political, religious or ideological agenda. We acknowledge that some scholars may define terrorism differently and this ultimately influences their approach to the terror-triage dilemma. In fact, this is where politics may enter through the back door.

However, it is important to emphasise that for the purpose of the discussion concerning the terror-triage dilemma, we do not insist on any particular definition of terror. To many, terror represents an instance of an egregious violent act that is deliberately targeted against innocent victims. Accordingly, the terror-triage dilemma serves as a case study for a special kind of situation in which a violent perpetrator and his or her victimswhose medical condition is more or less similar-are both in need of emergency medical treatment. Thus, even if one is not willing to define any specific mass or extreme violent event as terrorism (the ontological barrier), the core ethical dilemma concerning the medical triage in such situations remains in place with regard to non-terror situations.

Second, even if one assumes that from a practical perspective in some situations it is impossible to know immediately after a violent event that it is a case of terrorism or to validly identify the terrorist (the epistemic barrier), we suggest that the terror-triage dilemma is worth dealing with even merely as a thought experiment, since it captures conceptual dimensions that have not been discussed elsewhere. That having been said, we also think that there are often 'clear and obvious' situations 
that may be validly interpreted as terror immediately after their occurrence, and the identity of the terrorist may be clearly detectable.

If we return to the abovementioned example, if, during a period of time and in a zone of a known political or religious conflict, a person who by appearance belongs to one side of the conflict starts stabbing a group of elderly women or kids from the other side of the conflict and badly injures five of them, while screaming religiously oriented content, it can be safe to determine that it is a terror attack and the person with the bloody knife is a terrorist. Unfortunately, these kinds of events do happen. Even if one assumes that these are relatively rare events, it is crucial to clarify the ethical aspects that relate to these situations.

\section{THE 'NO EXCEPTIONS' APPROACH}

As long as the terror-triage dilemma is discussed narrowly as a particular instance of emergency medical triage, its unidirectional resolution according to the 'worst-first' approach seems inevitable. This is so, because the conventional approach is by definition universal and impersonal. Thus, the territory of the dilemma is strictly confined by the inflexible non-contextualised boundaries of the conventional approach. Following the conventional 'worst-first' line of thought, the terror-triage dilemma can be easily solved: healthcare should be prioritised regardless of the question of whether the injured individual is a terrorist or a victim. If the terrorist is the most severely injured, he or she should be treated first. Terror, or any other instance of medical emergency that is caused by violence, does not make an exception to the universal 'worst-first' rule. The conventional view mandates that medical priority will always be made solely based on strict medical parameters. The maintenance of valueneutrality is considered a vital element in medical triage, according to this view.

Moreover, the proponents of the conventional approach may argue that the strength of their approach stems from their stringent ignorance of 'extraneous' value considerations. According to their view, the maintenance of value-neutrality in triage is the road to ethical conduct, in which only pure medical considerations are allowed.

\section{VALUE-NEUTRALITY CAN LEAD TO INJUSTICE}

In principle, a decision pertaining to an individual patient concerning the question of which injured organ should be treated first is a pure medical decision. However, the decision with regard to the question of which injured person should be treated first is ultimately a value-based decision. Therefore, the decision to treat the more severely injured terrorist is in principle no less value-based than the decision to treat the victim, regardless of the reasoning that leads to this decision. Obviously, these decisions would be based on medical knowledge, but there will be always a value-based component that justifies the principle according to which these decisions are made.

When the focus is on the internal mental experience of the healthcare provider, it may be hard to understand why a valueneutrality approach is actually not value-neutral. For the individual healthcare provider, who may be struggling with powerful resentful emotions while treating a perpetrator of violence, the worst-first approach may feel like the highest degree of virtuous professional conduct. Indeed, from a virtue-based perspective, the mental effort to maintain value-neutrality is praiseworthy. Nevertheless, justice-oriented dimensions of morality, which may contradict the virtuous euphoria that accompanies the subjective neutrality-maintenance effort, cannot be ignored.
Thus, taken as a moral approach, by making value-oriented considerations 'extraneous' to medical priority setting, the 'no exceptions' approach is not value-neutral. It practically enacts a value-based decision that the mechanism of the priority setting is always more important than the practical outcomes. It sanctifies the end point priorities that are set by the 'worst-first' rationale only because it has been determined by the 'worst-first' calculation. In other words, the means justify the ends.

However, when a rule is applied universally, its inflexibility may become a disadvantage. The 'no-exceptions'-based decision to be indifferent to the extreme case of terror is a deliberate decision to turn a blind eye and maintain neutrality while ignoring significant moral considerations that relate to acts of terror. When physicians fulfil their sacred duty of healing they should not invariably apply a universal-impartial approach, since this may be inequitable in situations such as the terror-triage dilemma.

The special case of terrorism exposes the weak spot of the conventional approach, when it is applied universally, neglecting any contextual considerations at all times and in all circumstances. In almost all situations, the 'worst-first' system works well. However, in rare situations, such as the terror-triage dilemma, context-ignorant value neutrality or value-blindness leads to societal injustice, as will be explained in detail in the subsequent sections.

\section{THE 'VICTIM-FIRST' APPROACH}

The 'victim-first' approach maintains that withholding medical treatment from terrorists in situations in which there are no other individuals or victims that require immediate medical intervention would be inappropriate, since the duty to help injured terrorists stems from the physicians' core-even sacred - duty to heal the sick.

However, terrorists should not be treated before their victims in situations in which the delay in the provision of medical intervention to the victims may severely compromise the victims' condition. The justice-oriented justification that leads to this conclusion relates to three dimensions: retributive justice, distributive justice and corrective justice. In essence, the three dimensions may be presented as follows:

1. Terrorists do not deserve the right of higher priority in the terror-triage dilemma (retributive justice).

2. The higher societal merit of the victims makes them eligible for higher priority (distributive justice).

3. The terrorist, who intentionally caused the victims' injury, should be of lower priority than the victims (corrective justice).

Although some overlap between the three dimensions exists, each dimension is presented as an independent argument in order to highlight the different aspects of the justice-oriented argument. Not all the dimensions are necessary in order to justify the prioritisation of the victims. For example, even if one rejects the retributive argument, the other two dimensions-the distributive justice and the corrective justice-are strong enough to support the higher priority of the victims on their own.

\section{The retributive justice argument}

From a retributive perspective, the extreme egregious nature of terrorists' actions justifies an extreme response towards them. The perpetrator of terror's immediate objective is to kill and annibilate life. The non-discriminating nature of terror blindly harms civilians, including children, women and the elderly. Thus, from a retributive perspective, it is justified to negate the right to priority of medical treatment for those who negate the right to life of their targets, civilian and combatants alike. Full 
humanitarian privileges should be reserved for those who respect human rights. While a 'rudimentary decent minimum' of rights, ${ }^{33}$ such as the right to medical treatment, should be granted to terrorists on humanitarian grounds, the right to priority of medical treatment is not among these basic rights.

The retributive perspective is explicitly value-oriented. The reason for making terror an exception to the need-oriented conventional rule rests upon the extreme viciousness of terrorism. Terror is a special case of serious and deliberate act of violence, which is especially wrong because it intentionally kills and injures innocent individuals. ${ }^{10}$ From a moral perspective, the foundation of medicine seems to be the opposite social phenomenon to terrorism; while physicians blindly heal, terrorists blindly kill. Therefore, from a retributive point of view, it is justified to withhold the privilege of 'blind medical triage' from terrorists as a quasi-punitive countermeasure due to their inferior moral status. The sanction of downgrading their priority directly parallels the gravity and nature of their wrongdoing.

This deontological approach may further be augmented by consequentialist considerations. For example, downgrading priority of medical treatment for terrorists may deter future potential terrorists, who know that they may not receive life-saving treatment in case they are severely injured while committing a multicasualty terror attack. In addition, from a utilitarian perspective it seems unwarranted to invest precious time and resources on emergency treatment to terrorists when there is no expectation of reciprocity.

\section{The distributive justice argument}

According to Aristotle, distributive justice means that 'the same equality will exist between the persons and between the things concerned... awards should be according to merit... The just, then, is a species of the proportionate... equality of ratios... the unjust is what violates the proportion.... ${ }^{1}$ In other words, distributive justice is defined as an allocation of resources in accordance with the relative merit of each participant. ${ }^{34}$ Aristotle is aware of the fact that 'merit' may be determined differently by different socio-political orientations. Regardless of the specific criteria for distribution, what makes it just is its accordance with 'geometrical proportion'. Thus, in order to determine who gets a bigger share, all that is required is to compare the relative merits of each participant and allocate the resources accordingly. It becomes clear that the most crucial point in defining a just distribution is related to the specific criteria of 'merit'.

In most triage situations (such as earthquakes, hurricanes, tsunamis, etc), where the medical team lacks prior knowledge about the identity of the victims, it is practically and principally impossible to categorise the injured participants on the scene according to their merit. Thus, due to this epistemic barrier, it should be assumed that each participant has equal merit, which leads to the application of the priority-based-on-need criterion since it is the only measurable variable easily accessible to the medical team.

However, scenes of extreme, violent events may be unique situations in which the medical team may have access to knowledge of the attitudes and behaviour towards the society of the injured participants.

A terror attack is a direct act against society, its symbols and values. The deleterious effects of terror transcend the personal injury of its innocent victims. Terrorists choose terror because they are aware of the vast multilayered ramifications it has on the society they intend to harm. Therefore, once healthcare providers are aware of the fact that the cause of the medical emergency situation is a terror attack and the identity of the terrorist is evident and verified, the scene becomes significantly different from a standard triage scenario.

In spite of the fact that it is not possible to perform a deep moral examination of the overall virtues and behaviour of each individual in the triage scene, it is possible to set a threshold criterion that may help in making a dichotomous categorisation of the participants in the resource-limited situation. From the 'distributive geometry' perspective, in the terror-triage dilemma, it is not required to reach an absolute quantitative value of one's 'merit'. Since resources are proportionally delivered in parallel to 'merit', it is good enough to determine a relative-rather than absolute-'merit'-status in order to decide who should get a bigger share in the societal resources.

Given the nature and purpose of terror, it can be argued that each of the injured victims has a greater merit than that of the terrorist. Even if terrorists are deserving of more than a 'rudimentary decent minimum' of rights, as opposed to the retributive argument, their rights cannot supersede the rights of the victims. The terrorist is the only injured participant that intentionally and directly targeted and waged aggression against the society from which he or she now claims medical resources. Thus, distributive justice based on the proportionality principle mandates that medical resources be allocated first to those who did not demonstrate a negative attitude towards the society.

This is not a punitive act against the 'bad' terrorist, but rather it is an inherent consequence of his or her antisocial behaviour (in the literal sense) in this particular event. The victims' priority of medical care is upgraded once it becomes evident that there is a participant in the triage 'equation' whose actions turned out to be against society. As a result, the terrorist's right to medical priority is downgraded. The 'distributive geometry' of this situation makes the victims eligible for higher medical priority in situations of limited resources.

Moreover, according to some legal systems, a person can gain medical priority based on prior altruistic behaviour, for example, with regard to eligibility as an organ transplant recipient. ${ }^{35}$ Similarly, a person may lose priority to others in a triage situation based on prior extreme antisocial behaviour, although the right to treatment remains the same as that of the others. $^{33} 36$

\section{The corrective justice argument}

In most medical triage situations, arguably the most important value that should be taken into consideration is that of distributive justice. ${ }^{37}$ As previously mentioned, following various sources of medical emergencies (such as earthquakes, hurricanes, tsunamis, etc), all the victims are equally inflicted by the same natural force, which does not in itself require any medical treatment. However, the terror-triage dilemma qualitatively differs from most medical triage situations in the sense that the perpetrator of terror is the cause of the medical emergency but at the same time he or she is also a participant in the subsequent distribution of medical resources. This reality brings to the table an additional set of considerations pertaining to the specific relationship between the terrorist and the victims, which relates to the concept of corrective justice.

Corrective (or rectificatory) justice relates to situations in which $\mathrm{A}$ has gained $\mathrm{X}$ by making $\mathrm{B}$ lose $\mathrm{X}$, or A inflicted injury and $B$ has received it. ${ }^{1}$ This concept is not concerned with allocation of goods in general, but with restoring the equality between people when one has victimised the other. According to Aristotle, corrective justice is arithmetical-what A has gained should be taken from him and given back to B. Injustice 
occurs when, relative to the baseline where the two parties entered the situation, one party realises a gain and the other, a corresponding loss. The correction of this injustice is effected by re-establishing the initial condition, by depriving one party of the gain and restoring it to the other. ${ }^{38}$

There is a major difference between distributive and corrective justice that is relevant to the terror-triage dilemma. As opposed to distributive justice, the merit of the involved participants does not play a role in corrective justice. As Aristotle says

"It makes no difference whether a good man has defrauded a bad man or a bad man a good one... the law looks only to the distinctive character of the injuries, and treats the parties as equals where one is in the wrong and the other is being wronged, and if one inflicted injury and the other has received it". ${ }^{1}$

The normative position of each party is determined only through the position of the other, which is the mirror image of it. $^{38}$ In other words, corrective justice does not involve a comparison between multiple parties based on some value-based criteria, but rather it focuses on two parties only and analyses their interrelationship in order to determine, with regard to a specific event, who the perpetrator and victim are and what each party has gained or lost.

The description above illustrates why in the terror-triage situation corrective justice considerations must be included. The terrorist, who bears causal responsibility for the injuries of the other participants, has a duty to correct the loss he or she inflicted upon the victims. The insult to the victims is above all the loss of their health; they entered the terror attack scene healthy and ended up severely injured. This is exactly the gain of the terrorist and what he or she deliberately tried to achieve. Thus, under conditions of limited resources, someone has to bear the 'burden' of lower priority of medical management. In a 'head-to-head' comparison between the terrorist and each of the victims, corrective justice consideration leads to the conclusion that priority should be given to the victims since the terrorist has a duty to restore the health he or she 'took' from the victims, but not vice versa.

Most often, corrective justice plays a role in matters of civil law. For example, if $\mathrm{A}$ injures $\mathrm{B}$, corrective justice requires that A compensate B by monetary means (eg, by paying B's medical bills, covering B's lost income and offering compensation for pain and suffering). Obviously, corrective justice is not synonymous with physical retaliation (lex-talionis) or reparation in the sense that if A caused B's liver damage and B requires a transplant, then corrective justice would require $\mathrm{A}$ to donate his or her liver to $\mathrm{B}$.

Nevertheless, we think that corrective justice has a solid moral basis that extends beyond the territory of civil law and monetary compensation. For example, if A caused B's liver damage, and both $\mathrm{A}$ and $\mathrm{B}$ require a liver transplant, then corrective justice would require that $\mathrm{A}$ be prioritised to receive a liver donation from $\mathrm{C}$ before $\mathrm{B}$.

According to corrective justice, the terrorist would be downgraded in priority only with regard to the victims he or she personally injured, but not with regard to other law-abiding citizens who may require emergency medical treatment. However, according to the retributive (and possibly the distributive) consideration, the terrorist's right of priority may be downgraded even with comparison to any law-abiding citizens, even if their medical emergency is not directly related to the terror attack.

In summary, the justice-oriented victim-first approach is supported by the following arguments: the moral inferiority of the terrorist (the retributive dimension), the larger portion of social resources that the victims are eligible for (the distributive dimension) and the victims' overriding medical priority due to the terrorist's specific duty to restore their health (the corrective dimension).

\section{THE 'VICTIM-FIRST' EXCEPTION BEYOND TERRORISM}

The terror-triage dilemma thus serves as a case study of violent situations in which the victims should have a higher priority to limited emergency medical resources. One might ask: Should the victim-first approach be applied in every illegal situation in which the perpetrator of violence and its victim require medical treatment (eg, a bank robber who injured clients during a robbery and in the process was himself injured)?

Although it may be hard to draw a sharp line between diverse illegal violent assaults, we think that the extreme measure of downgrading priority of medical emergency care should be reserved for the most extreme manifestations of egregious human behaviour. Hence, victim-first exception should be restricted only to situations that qualitatively resemble terrorism.

Most violent criminal acts are not deliberate acts of intentional killing and injuring as many innocent people as possible. Although criminal acts are also considered in a broader sense as crimes against society, the antisocial component is semimetaphorical and indirect in comparison to terrorism, which engages in a direct act against society.

Although the corrective justice dimension is indeed equally relevant to medical emergencies that have been caused by criminals (since this argument is specifically linked to causal responsibility and not to the gravity of the action or the blameworthiness of the agent), the corrective justice argument is not sufficient by itself to negate the need-based priority procedure. Causal responsibility is an integral part of the justice-based approach and it is additive to the retributive and distributive dimensions. In other words, the corrective justice consideration is not sufficient to elicit the victim-first approach in all medical emergencies caused by humans (such as unintentional motor vehicle accidents), but rather it is reserved only for the most extreme deliberate human-initiated events. This distinction explains the gravity and blameworthiness of terror-like violent events in comparison to other crimes.

Thus, in principle, one can imagine an extreme violent event (in terms of the viciousness of the perpetrator and the nature of his or her action) that crosses the 'merit' threshold to the extent that the criminal should be deprived of priority of medical care, such as a public mass shooting on an academic campus by a furious student. In fact, scholars who emphasise the component of the means-as opposed to goals (eg, political, religious)-in the characterisation of terrorism may argue that any violent event of this nature should be defined as a terror attack.

\section{SOCIETAL JUSTICE AND MEDICAL CONVENTIONS}

In addition to the justice-oriented considerations that justify the victim-first approach, there is another disturbing aspect of the 'no-exceptions' approach that makes it hard to digest. It relates to the question of who owns the terror-triage dilemma. Is it a medical dilemma or a societal dilemma? There is no doubt that medical personnel are the ones who directly confront this dilemma; however, the following illustrates how no one can ignore the broader societal context of the dilemma.

Let us consider the terror-triage situation a few seconds before the terror attack has taken place. A man wielding a knife while screaming religious or politically oriented content starts running towards a group of civilian teenage bystanders. Let us 
assume that it is clear and obvious that this man is a terrorist and that he is about to commit a terror attack. This is a case in which the teenagers have the right to self-defense and if there is no other alternative, it would be morally and legally permissible to kill the would-be-terrorist in order to prevent the violent assault. Moreover, according to some jurisdictions, society's right of self-defense can be extended to 'targeted killing' of suspected terrorists even in less clear and obvious scenarios. ${ }^{39-43}$

Self-defense means that it is legitimate to save the would-be-victim, even if it means actively killing the would-be-terrorist. Put differently, the would-be-victims' right to live overrides the perpetrator of terror's right to live.

Immediately after the terror attack, the status of the perpetrator has changed from would-be-terrorist to a terrorist and the would-be-victims have become victims. In the terror-triage dilemma scenario, both of them are now severely injured, although the terrorist is in worse condition. At this point the 'no-exceptions' approach is hard to digest, since it is not clear why at this point suddenly the terrorist's right to life overrides the victim's right to life. On what basis has the moral equation been reversed? Does the terrorist's worse medical condition justify the ethical flip-flop in the inter-relationship between the terrorist and the victims? What is the rational justification for this miraculous 'moral reset'?

The terror-triage situation did not start at the time of the triage. The terror attack caused by the terrorist is the starting point of the dilemma, both factually and ethically. Medicine should not always be practised as if medical situations are occurring in a moral and societal vacuum. The conventional valueneutral paradigm is not powerful enough to reset the moral and societal aspects of the terror-triage dilemma. Put differently, the medical field does not have ownership of the terror-triage situation. Medical conventions that may be appropriate in almost any other situation may not be compelling enough to ignore and dismiss broader societal justice-oriented considerations. A convincing specific argument that is tailored to the terror-triage dilemma is required, in order to justify the application of the worst-first approach in such situations. Otherwise, the 'no exceptions' approach is conventional dogmatism.

The principle of negating criminals' privileges that are related to situations which they have unlawfully and deliberately caused - ex turpi causa oritur non actio-is a well-recognised consideration in various matters of public policy. ${ }^{44-47}$ Thus, the 'successful' execution of the terror attack should not provide the terrorist with a promotion of priority to medical treatment, even if he or she has been badly injured as a consequence of his or her wrongdoing.

\section{MORAL SENTIMENTS AND MORAL REASONING}

It may be anticipated that some proponents of the 'worst-first' doctrine would consider the 'victim-first' approach a politically biased emotive response predicated on vengeful sentiments. Hence, giving priority to the victims would count as a failure to act professionally and rationally when facing an emotionally challenging situation. Implicitly, these scholars may perceive those who prioritise victims as morally inferior due to the apparently retaliatory flavour that could be ascribed to their position. To these critics, any rational arguments presented to support the prioritisation of the victims would be considered revenge in a mask.

However, the argument that some physicians in extreme situations may prioritise victims due to vengeful sentiments does not necessarily prove that the 'victim-first' approach cannot be justified with solid ethical arguments. In fact, intuitions and sentiments have a major role in people's moral thinking and behaviour. ${ }^{48}$ Justice and desert intuitions are valuable resources for moral human behaviour that should not be ignored by individuals and policy makers. ${ }^{49}$ These embedded intuitions, in some situations, poorly match rational reasoning, but they may also be in perfect accordance with sound moral arguments. The terror-triage dilemma illustrates how moral intuitions may go hand-in-hand with lucid rational arguments.

Hence, it would not be fair to accuse the terror-exception approach as being masked revenge, since it could be equally counterargued that the 'no-exceptions' approach and its apparent value-neutral discourse is actually a manifestation of conservative stagnation, induced by fear of change, or even masked political-correctness. At times, moral reasoning just goes hand-in-hand with healthy moral intuitions. Applying a worstfirst triage in all situations ignores these basic intuitive and rational considerations.

\section{DYNAMISM AND DIVERSITY IN MEDICAL ETHICS}

Medical practice is a dynamic field. Guidelines are modified and new conceptions arise whenever advanced knowledge and innovative technologies appear. The same is true with regard to medical ethics. New conceptual challenges and social developments lead to modifications in medical practice due to ethical paradigm shifts. ${ }^{50}{ }^{51}$ Even the arguably most elementary ethical tenet of medicine, primum non nocere (first, do not harm), has been changed throughout history. For example, according to the Hippocratic Oath, physicians should not under any circumstances be involved in assisted-death or abortion. This absolute Hippocratic prohibition is no longer valid in many cultures. ${ }^{52} 53$

The same is true with regard to the history of triage. Advanced medical understanding, new technologies and value-oriented considerations have modified triage throughout the last two centuries. Not long after its inception, Larrey's 'worst-first' approach was partially abandoned, only to be modified again and again in the years that followed. ${ }^{35}{ }^{54}$ Larrey's practice can be well understood in light of the era in which he lived. Inspired by the French Revolution, which held the view that all were equal, he provided treatment 'without regard to rank or distinction'. ${ }^{7}$ In the political atmosphere at that point of time in France, 'no one dared to question Larrey's triage system for fear of being deeded aristocratic'. ${ }^{6}$ It is worth mentioning that Larrey's worst-first approach appeared to be implemented only with regard to his fellow French troops. In his Memoirs of Military Surgery, ${ }^{7}$ there is indeed ample evidence that he devotedly treated the injured and the sick of other nationalities. However, we could not find any evidence for the claim that in the face of an emergency he provided treatment to worst-injured enemy soldiers before his fellow French soldiers. ${ }^{i}$ Furthermore, there is evidence of numerous practices that would be ethically questionable today (such as mentioning his patients' names or performing quasi-research without informed consent).

That having been said, there are things that will not and should not be changed. Among them is the physician's foremost duty to heal. Therefore, it is hard to imagine an ethically valid

\footnotetext{
${ }^{\mathrm{i}}$ We reached this finding by conducting a computer search of the English translation of Larrey's book (Memoirs of military surgery: And campaigns of the French armies, on the Rhine, in Corsica, Catalonia, Egypt, and Syria: at Boulogne, Ulm, and Austerlitz: in Saxony, Prussia, Poland, Spain, and Austria) for various key words, such as nationality, distinction, rank, treatment, before, first, without regard to, etc.
} 
approach that in principle negates medical treatment to terrorists. To treat terrorists is a noble act of humanism; however, to treat them before their victims may be associated with injustice. The discussion above has attempted to indicate that the 'victimfirst' approach is appropriate as an alternative to the 'worst-first' approach in extreme manifestations of violence and that it can be justified based on notions of justice and common-sense moral intuitions.

Nevertheless, two caveats must be mentioned with regard to the application of the 'victim-first' approach. First, the procedural justice principle dictates that the 'victim-first' approach should be applied blindly in all terror-like situations, regardless of the personal identity (eg, nationality, religion and ethnicity) of the perpetrator or the victim. The legitimacy and credibility of the 'victim-first' approach is dependent on strict adherence to this principle. Otherwise, it would be highly suggestive that the 'victim-first' approach is biased by a politically oriented interest. The victim comes before the perpetrator due to the nature of the perpetrator's action, not his or her personal identity.

Second, we would like to reemphasise that the 'victim-first' approach may be appropriate only in situations in which it is clearly evident that the medical emergency is a case of terrorlike violence and there is no doubt with regard to the identity of the perpetrator. Otherwise, it would be impractical and unjustified to add another burden on to the healthcare providers' shoulders, whose full attention should be focused on the pure medical aspects of the emergency situation.

\section{FUTURE DIRECTIONS AND CONCLUSION}

If one basically accepts the 'victim-first' rationale, additional questions immediately arise. For example, should the perpetrator's downgraded priority of medical care apply to the entire length of medical treatment-even after several months? Or does this only apply during the triage situation? Should medical professionals at times upgrade the perpetrator's priority based on utilitarian security considerations (eg, when the terrorist holds valuable information)? Should 'conscientious objection' (eg, to treat the perpetrator or victim first) be allowed to healthcare providers in terror-triage-like situations? Should 'victimfirst' exceptions be allowed-or even be recommended-in specific unique situations such as a physician coming on the scene and noting that his wife or child is one of the victims?

These are relevant and important questions that open the discussion to other ethical problems (such as boundary violations of medical intervention in governmental interests, diversity in medical practice based on ethical considerations, etc), which are beyond the scope of this paper. It is hoped that none of these issues would surface at all in the first place, at least in the medical systems of high-income countries given appropriate and adequate medical services that could attend to the needs of all without the need to prioritise limited resources.

Our contribution in this paper is limited to the presentation of the dilemma and the suggestion that at least in some cases of an agreed-upon clear and obvious egregious violent act deliberately targeted against innocent victims, the victims should be granted medical priority over their perpetrator.

To sum up, in ethics, answers are not always clear and there may be more than one answer to a given dilemma. Thus, in situations when societies face tragic choices and where fundamental social cultural values are at stake, they must attempt to make allocations in ways that preserve the moral foundations of social collaboration. ${ }^{55}$ What is important however is that the questions are asked, that discussion abounds and that there be respect for a range of responses and opinions.
Given the perplexing dilemmas Western society is facing due to terror in various arenas, it would be naïve to suggest that in the medical arena 'business should be as usual', without any revisiting or exploring of conventional dogmas. In this paper, we wish to open the discussion to diverse opinions regarding the issue of medical triage. Conventional 'worst-first' triage is appropriate under almost all situations; however, the unique characteristics that are illustrated via the terror-triage dilemma cannot be ignored.

Following Aristotelian insights, we find the 'victim-first' exception 'equitable... it is just and is better than one kind of justice'. ${ }^{1}$

Acknowledgements We thank the three anonymous reviewers for valuable comments on earlier versions of this manuscript and Professor Paul Appelbaum for an insightful discussion pertaining to the subject matter.

Disclaimer The content of this paper represents the authors' view.

Competing interests None declared.

Authors' statement This paper has not been published elsewhere and it has not been submitted simultaneously for publication elsewhere. The authors declare no conflicting interests.

Provenance and peer review Not commissioned; externally peer reviewed.

\section{REFERENCES}

1 Aristotle, Ross WD, Brown L. The Nicomachean ethics. Oxford: Oxford University Press, 2009.

2 Petrini C. Triage in public health emergencies: ethical issues. Intern Emerg Med 2010;5:137-44.

3 Kipnis K. Overwhelming casualties: medical ethics in a time of terror. Account Res 2003; 10:57-68.

4 Burris DG, Welling DR, Rich NM. Dominique Jean Larrey and the principles of humanity in warfare. J Am Coll Surg 2004;198:831-5.

5 Beebe RWO, Myers JW. Professional paramedic: Volume 3. Clifton Park, N.Y: Delmar Cengage Learning, 2012.

6 Nestor P. Baron Dominique Jean Larrey 1766-1842. Australas J Paramed 2003;1:1-7.

7 Larrey DJ, Hall RW, Cushing J, et al. Memoirs of military surgery: And campaigns of the French armies, on the Rhine, in Corsica, Catalonia, Egypt, and Syria: at Boulogne, UIm, and Austerlitz: in Saxony, Prussia, Poland, Spain, and Austria. Baltimore: Joseph Cushing, 1814.

8 Henriksen A. Jus ad bellum and American targeted use of force to fight terrorism around the world. J Conflict Security Law 2014;19:211-50.

9 Khatchadourian H. The morality of terrorism. New York: P. Lang, 1998.

10 Nathanson S. Terrorism and the ethics of war. Cambridge: Cambridge University Press, 2010.

11 Osiel M. The end of reciprocity: terror, torture, and the law of war. New York: Cambridge University Press, 2009.

12 Steinhoff U. On the ethics of war and terrorism. Oxford: Oxford University Press, 2007.

13 Wellman C. What is Terrorism? Terrorism and Counterterrorism-A Moral Assessment Springer 2013:1-17.

14 Walzer M. Just and unjust wars: a moral argument with historical illustrations. 4th edn. New York: Basic Books, 2006.

15 Fischer MP. Applicability of the Geneva Conventions to "Armed Conflict" in the War on Terror. Fordham Int L J 2006;30:509-34.

16 Yoo JC. The status of soldiers and terrorists under the Geneva conventions. Chinese J Int L 2004;3:135-50.

17 Coady CAJ. The morality of terrorism. Philosophy 1985;60:47-69.

18 Ganor B. Defining terrorism: is one man's terrorist another man's freedom fighter? Police Pract Res 2002;3:287-304.

19 Grozdanova R. 'Terrorism' - too elusive a term for an International Legal Definition? Neth Int Law Rev 2014;61:305-34

20 Hodgson JS, Tadros V. The impossibility of defining terrorism. New Crim Law Rev 2013;16:494-526.

21 Primoratz I. What is terrorism? J App/ Philos 1990;7:129-38.

22 Shanahan T. Betraying a certain corruption of mind: how (and how not) to define 'terrorism'. Critical Stud Terrorism 2010:3:173-90.

23 Schmid AP. Frameworks for conceptualising terrorism. Terrorism Political Violence 2004; 16:197-221.

24 Tommis P. The Terrorism of 'Terrorism'. In: Sterba JP, ed. Terrorism and international justice. New York: Oxford University Press, 2003:47-66.

25 Shapira SC, Hammond JS, Cole LA. Essentials of terror medicine. New York: Springer, 2009. 
26 Moreno JD. In the wake of terror: medicine and morality in a time of crisis. United States: MIT Press, 2003.

27 Gross ML. Bioethics and armed conflict: mapping moral dimensions of medicine and war. Hastings Cent Rep 2004;34:22-30.

28 Miles SH. Medical ethics and the interrogation of Guantanamo 063. Am J Bioeth 2007:7:5-11.

29 Bloche MG, Marks JH. Doctors and interrogators at Guantanamo Bay. N Engl J Med 2005;353:6-8.

30 Rubenstein LS, Annas GJ. Medical ethics at Guantanamo Bay detention centre and in the US military: a time for reform. Lancet 2009;374:353-5.

31 Gesundheit B, Ash N, Blazer S, et al. Medical care for terrorists - to treat or not to treat? Am J Bioeth 2009:9:40-2.

32 Bloche MG, Marks JH. When doctors go to war. N Engl J Med 2005;352:3-6.

33 Schneiderman LJ, Jecker NS. Should a criminal receive a heart transplant? Medical justice vs. societal justice. Theor Med 1996;17:33-44.

34 Perry R. The role of retributive justice in the common law of torts: a descriptive theory. Tennessee Law Rev 2006:73:177-236.

35 Dalal AR. Philosophy of organ donation: review of ethical facets. World J Transplant 2015:5:44-51.

36 McKneally MF, Sade RM. The prisoner dilemma: should convicted felons have the same access to heart transplantation as ordinary citizens? Opposing views. J Thorac Cardiovasc Surg 2003;125:451-3.

37 Moskop JC, Iserson KV. Triage in medicine, part II: underlying values and principles. Ann Emerg Med 2007;49:282-7.

38 Weinrib EJ. Corrective Justice in a Nutshell. Univ Toronto Law J 2002:52:349-56

39 Ben-Naftali 0, Michaeli K. Public Committee Against Torture in Israel v. Government of Israel. Case No. HCJ 769/02. Am J Int Law 2007;101:459-65.

40 Hunter TB. Targeted killing: self-defense, preemption, and the war on terrorism. J Strateg Secur 2009;2:1-52.
41 MacDonald S. The lawful use of targeted killing in contemporary international humanitarian law. J Terrorism Res 2011;2:126-144.

42 Matos H. Offensive counterterrorism targeted killing in eliminating terrorist target: the case of the USA and Israel. JANUS.NET: e-journal Int Relations 2012;3:114-138.

43 Ramsden M. Targeted killings and international human rights law: the case of Anwar Al-Awlaki. J Conf Secur Law 2011;16:385-406.

44 Charles D. Ex turpi causa returns to the English law of torts: taking advantage of a wrong way out. Common Law World Rev 1984;13:15-31.

45 Macdougall B. Ex turpi causa: should a defence arise from a base cause? Sask L Rev 1991;55:1-41.

46 Mance J. Ex turpi causa-when Latin avoids liability. Edinburgh Law Rev 2014;18:175-92.

47 Reed A. Ex turpi causa and gross negligence manslaughter. J Crim Law 2005:69:132-45.

48 Haidt J. The emotional dog and its rational tail: a social intuitionist approach to moral judgment. Psychol Rev 2001;108:814-34.

49 Robinson PH. Intuitions of justice and the utility of desert. Oxford: Oxford University Press, 2013.

50 Gold A. Physicians' "right of conscience": beyond politics. J Law Med Ethics 2010:38:134-42

51 Jotterand F. The Hippocratic Oath and contemporary medicine: dialectic between past ideals and present reality? J Med Philos 2005;30:107-28.

52 Miles SH. The Hippocratic Oath and the ethics of medicine. United States: Oxford University Press, 2004.

53 Winton RR. Hippocratic Oath as anachronistic. Med J Austr 1979;2:365-6.

54 Iserson KV, Moskop JC. Triage in medicine, part I: concept, history, and types. Ann Emerg Med 2007:49:275-81.

55 Calabresi G, Bobbitt P. Tragic Choices. New York: W.W. Norton \& Company, 1978. 